\title{
Towards communication and information access for Deaf people
}

\author{
Edwin Blake*, William Tucker ${ }^{\dagger}$, Meryl Glaser ${ }^{\ddagger}$ \\ * Department of Computer Science, University of Cape Town, South Africa \\ †Department of Computer Science, University of the Western Cape, South Africa \\ $\ddagger$ Deaf Community of Cape Town, South Africa
}

\begin{abstract}
In tightly circumscribed communication situations, an interactive system resident on a mobile device can assist Deaf people with their communication and information needs. The Deaf users considered here use South African Sign Language and information is conveyed by a collection of pre-recorded video clips and images. The system was designed and implemented according to our method of community-based co-design. We present several stages of the development as a series of case studies and highlight our experience and the implications for design. The first stage involved ethnographically inspired methods such as cultural probes. In the next stage we co-designed a medical consultation system that was ultimately dropped for technical reasons. A smaller system was developed for pharmaceutical dispensing and successfully implemented and tested. It now awaits deployment in an actual pharmacy. We also developed a preliminary authoring tool to tackle the problem of content generation for interactive computer literacy training. We are also working on another medical health information tool. We intend that a generic authoring tool be able to generate mobile applications for all of these scenarios. These mobile applications bridge communication gaps for Deaf people via accessible and affordable assistive technology.
\end{abstract}

KEYWORDS: assistive technology, authoring tools, co-design, health care, information and communications technology for development, international computer drivers licence, mobile computing, pharmacy

\section{CATEGORIES:}

- Human-centered computing $\rightarrow$ Empirical studies in interaction design

- Human-centered computing $\rightarrow$ Ubiquitous and mobile computing

- Human-centered computing $\rightarrow$ Accessibility design and evaluation methods

- Human-centered computing $\rightarrow$ Systems and tools for interaction design

- Human-centered computing $\rightarrow$ Accessibility systems and tools

- Social and professional topics $\rightarrow$ People with disabilities

- Social and professional topics $\rightarrow$ Cultural characteristics

- Applied computing $\rightarrow$ Computer-assisted instruction

\section{INTRODUCTION}

The aim of our work is to uncover design methods that enable us to provide Deaf users with a practical way of communicating and accessing knowledge in their own language, South African Sign Language (SASL). This language is a vital part of the Deaf identity which combines cultural pride, disability and lack of economic strength. A large number of Deaf people use SASL; it is estimated that there are at least 500 000, while the Deaf Federation of South Africa (DeafSA) put the number of SASL users at over 1.5 million [1] making it one of the larger language groups in the country.

Following international convention we write 'Deaf' with a capital D to denote a cultural, linguistic group who uses, in this case, SASL as their preferred language.

Email: Edwin Blake edwin@cs.uct.ac.za, William Tucker wdtucker@gmail.com, Meryl Glaser merylglaser@gmail.com
This is as opposed to 'deaf' with a small d, which refers to a medical condition, i.e., loss of hearing. In the latter case the emphasis is only on the impairment. This is a self-identification by the Deaf community and moves the discussion beyond disability to one of digital exclusion of a disadvantaged community. Note that SASL is a unique language unrelated to any spoken language [2].

After two decades of democracy and transformation, telecommunication access is still clearly unequal, with Deaf people in South Africa even more disadvantaged than their hearing counterparts. Since 1994 there has been an increasing empowerment of Deaf people. SASL is accepted as a distinct language in its own right; although not an official language, it is directly mentioned in the constitution and it is recognised in the South African Schools Act [2].

The recent debacle with the interpreter at Nelson Mandela's memorial service on 11th December 2013 
(e.g., 'Sign Language Interpreter Translates Mandela Memorial ${ }^{1}$, led to an apology by the Minister of Arts and Culture, Paul Mashatile 3. This again emphasized the marginal position of Deaf people and challenges they face in communication even at the most important social events.

\subsection{Right of communication}

The notion of Universal Access is well established in the telecommunications field and has been extended in a number of ways in the Information and Communications Technology (ICT) field [4]. Our work returns to basic ideas of Universal Access for Communication. As noted by Msimang [5] the experience of South Africa is not one of Universal Access but the absence of it, coupled with attempts to redress the historic deprivation. He also points out that "In terms of the Telecommunications Act, the Minister may define the categories of 'needy' persons to whom assistance, in the form of subsidies, should be given". While the Deaf are included, there seems to have been little progress since the original discussion paper of 1998 [6].

\subsection{South African National Development Plan}

More recently in 2011, the National Development Plan (NDP) 7] declared general aims toward bridging the Digital Divide within South Africa. These included: ensuring 'access to low-cost, high-speed international bandwidth with open-access policies', extending broadband penetration to $100 \%$ by 2020 , and 'expanding ICT access in all rural areas' 7. The NDP specifically mentions efforts to integrate 'issues of disability into all facets of society, and ensure equitable service provision for persons with disabilities' 7]. However, the reality for the South African Deaf community is that smart phones are still very expensive, there are no government subsidies for their use and call charges are very high, access to the Internet is limited, national relay services do not exist and even if they did, the bandwidth required for sign language transmission in video is out of reach of most Deaf people.

\section{COMPUTER-BASED SUPPORT FOR SIGNED COMMUNICATION}

There are several uses to which computers can be put to assist Deaf people. One distinction is between enabling Deaf people to communicate with hearing people versus enabling Deaf people to communicate with each other. Another distinction is whether the input by the Deaf user is signing or text.

Text, as a medium, can potentially be used for Deaf people to communicate amongst themselves and with hearing people. This functionality is available on SMS ('text') messages on cell phones but these lack the instantaneous liveness indicator (to show someone is typing) found on alternative applications such as

\footnotetext{
${ }^{1}$ http://youtu.be/X-DxGoIVUWo
}

WhatsApp ${ }^{2}$. Liveness indicators help to create a sense of being co-present with the person being contacted. Deaf users are however inhibited from using text communication, particularly with hearing people, because many Deaf people have low levels of written language literacy (which of necessity takes place in a language other than their first language, namely SASL).

A service offered in some developed countries is that of a Video Relay Service (VRS), e.g., in the USA this is regulated by the Federal Communications Commission 8, 9]. With VRS a caller using sign language can communicate with a live VRS interpreter by using a video connection. The VRS interpreter signs the telephone conversation with the sign language user and voices to a hearing person who uses a standard telephone.

Another variant on using computers is to try to mimic VRS. This involves recognizing signing automatically and then encoding the recognized language for translation to voice. Such encoding can also be used for highly compressed transmission of the encoded signs. Such signs would then be recreated at the other end by a signing 'avatar'.

This whole effort depends on solving very complex problems in Artificial Intelligence. A leader in this research is Matt Huenerfauth at CUNY: see 'American Sign Language Animation 3 . There was also the European 5th Framework project ViSiCAST (Virtual human Signing: Capture, Animation, Storage \& Transmission, 2000-2002) and its follow-up eSign (20022004), which ended without seeming to make much impact 4 . A great deal of information is carried in facial expressions during signing and this has yet to be included in animations [10]. We are not expecting breakthroughs in this area soon.

\subsection{Context}

We work closely with a grassroots NGO called DCCT (Deaf Community of Cape Town ${ }^{5}$ which is staffed almost entirely by Deaf people and serves the needs of the larger Deaf community in the Western Cape. It was founded by members of the community in response to a dearth of services and support from mainstream and official sources. Most Deaf adults are semi-literate, at best, due to disadvantageous educational practices at schools for deaf learners. Many are unemployed, but those who are employed are often under-employed in menial jobs. This adversely affects the socio-economic level of the community as a whole. The Deaf community is underdeveloped in terms of ICT access and participation. In general we believe that ICT can be an enabling technology that supports development and empowerment.

\footnotetext{
${ }^{2}$ http://www.whatsapp.com

${ }^{3}$ http://eniac.cs.qc.cuny.edu/matt/research.html

${ }^{4}$ http://www.visicast.cmp.uea.ac.uk

${ }^{5}$ http://www.dect.org.za/
} 


\subsection{Research methodology}

Our approach has been one of Action Research, mostly viewed as a paradigm rather than a specific methodology [1] 12 13 14. The intention has been to achieve a dual aim of action intervention and research learning (unlike McKay and Marshall [11, we do not see that this requires a separate research and action cycle; our pragmatist epistemology avoids the separation of action and theoretical thinking [15). Given our background in experimental computer science this has always involved building computing artefacts, intervening with communities and then reflecting on the experience of using such a system.

The standard engineering aim in such situations is to build systems that are 'fit for purpose'. This implicitly depends on users who are able to state their needs clearly in terms that can be understood by technologists. It has become apparent that uncovering the specific purpose for which a new artefact is needed is problematic. Methods that deal with 'customers' are not adequate to encompass the context within which we practice ICT for Development (ICT4D). This is because such approaches assume customers are similarly educated and from the same culture and can express their needs in a language that Computer Science practitioners understand [16].

We now realize such notions of the aims of design have to be challenged. Designers have to work with users as co-designers and together identify the problem that needs to be addressed, the means of tackling the issues and then together decide on measures of success. The systems are designed and evaluated using Community-Based Co-Design (CBCD) methods [17.

\subsection{Community-based}

'Community-based' conveys the fact that we deal with groups of people rather than individuals, aligned with the African concept of 'ubuntu'; whereas in the developed world mobile phones and computers are geared to individual requirements [18. We need to remain sensitive to major cultural differences and develop ways of entering into design conversations with people who do not have technical skills but who are knowledgeable on their own needs and especially how their own communities operate. We realize too that there is no one community with whom we work. In every design situation there are many communities: the elders, the youth, women, migrants, people with disabilities, and so on. Each of these has to be given a voice in design. In order for that to happen we must recognize groups of stakeholders, identify gatekeepers and consider how all the diverse needs might be investigated.

\subsection{Co-design}

'Co-design' derives from the application of the action research paradigm in a design setting: both the computer experts and the community members are designers on an equal footing and work cooperatively. There is an ambiguity in the use of the term 'co-design' in the literature. For some co-design is something done in the early stages of eliciting user requirements and signifies using techniques such as cultural probes, generative sessions, technology probes and so forth. From our point of view this is better called 'early stage co-design' [19] 20] (also see Marti and Bannon [21] for a critical discussion of different ways of managing user-involvement). We employ all of those techniques where appropriate but co-design goes further when combined with action research and continues to all stages of artefact development and evaluation. This is part of a trend in empowering people and moving away from a rhetoric of 'compassion' 22]: from 'ICT for D' to 'D with ICT'.

Once stakeholders have been identified, a common language (or 'metaphor' as it is sometimes called in computing) has to be developed. With sophisticated users this language can be based on crude mock-ups of a computer interface ('paper prototypes') since such people can readily imagine how this might work in an ICT artefact. Where a common understanding of technology does not exist, co-designers have to be given insight into the possibilities offered by the technology by means of approximations implemented using technology.

A key feature of co-design is for technical experts to keep their own design decisions in abeyance. It is a serious mistake to commit (psychologically) to a design solution before the co-designers have found their voice.

\section{COMMUNICATION ACCESS FOR DEAF PEOPLE IN CIRCUMSCRIBED SITUA- TIONS}

We have spent many years working on various aspects of supporting communication access for Deaf people. For this part of the project we look at issues that arise when Deaf people want to access services provided by the larger hearing culture within which DCCT is situated. Detailed contextual enquiry and the use of generative methods produced a number of possible scenarios, including reporting a crime at a police station (Figure 1), consulting a doctor at a hospital, and dealing with the department of Home Affairs. A generic authoring tool would be ideal to create tools that are able to handle multiple scenarios (Section 3.3).

The scenario jointly selected by the Deaf community and researchers for initial detailed design and prototyping was medical consultation. The trial itself was very successful in proving the usefulness of the approach (Section 4.1. The drawback uncovered was that a medical consultation was too broad and open-ended and would need much more content as well as a VRS. We wanted to do real field trials and so we decided to switch to a more constrained scenario, namely dispensing medication at a hospital pharmacy (Section 4.2).

In parallel we explored computer supported computer literacy training, which also gave us the opportunity to build our first version of an authoring tool (Section 4.3). 


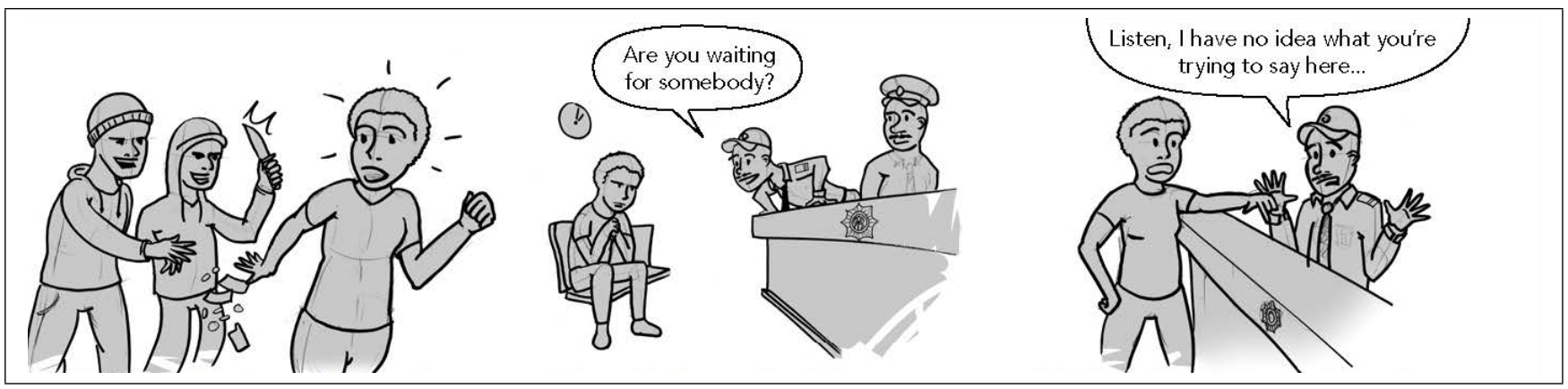

Figure 1: Reporting a crime scenario: "I tried to explain what happened, but there was no one around who knew sign language. I learned how to speak at school, but every time I meet people like this, they act like I'm retarded or something."

\subsection{SignSupport}

We have created a number of prototype systems via the CBCD method. These systems all share a common basic architecture we have called SignSupport (Figure 2).

SignSupport targets the communication needs of Deaf people in circumscribed contexts where they want to access services in a community that mostly cannot sign. Such situations would include critical situations such as visits to a medical doctor or getting prescription medication from a hospital pharmacy, or learning contexts such as accessing health information or learning how to use a computer.

We have already piloted various aspects of the system and executed detailed designs of others. The current phase of our ongoing research project with the Deaf community, namely communication in circumscribed contexts, started with requests from the community. One was an interest in gaining computer literacy and the other was for support in civic engagement (for example, doctors at hospitals, police, etc.).

The key to the widespread use of SignSupport will be the ability to create content. This is an intensive process that requires input from domain specialists in the context of application. For each scenario the most common possible interactions within the frame of communication have to be mapped out.

\subsection{Generic use of SignSupport based systems}

The general use of SignSupport is for those situations where the communication needs can be constrained by the context such that sequences of pre-recorded signing video clips suffice to inform the Deaf user. The hearing user may need some training in the use of the communication system.

All communication takes place by means of the mediation provided by a mobile phone in possession of the Deaf user. This phone contains all the material needed to facilitate communication and is typically passed back and forth between the Deaf user and the hearing service provider.

The Deaf user can provide input by responding to questions built into the system. The prompts are provided by images and video clips. The Deaf user's responses are recorded and are displayed as text for the hearing service provider, who is given the phone and then records information in response to text questions. These saved responses result in the display of images and video sequences when the Deaf user gets the phone back.

Naturally such a system is only a partial solution and cannot cater for unusually complex situations. In such a case we plan to breakout to a VRS (see Section 22. Currently this faces technical and affordability hurdles. The VRS will have to receive state funding, a political problem. Secondly the phones will have to have high quality front facing cameras and high communications bandwidth that prioritizes video.

\subsection{Authoring tool}

Once a new scenario is identified for implementation, a domain expert will be included to help formulate the conversation/dialogue required. The authoring tool provides:

1. an interface for the dialogue to be mapped out and to populate the dialogue with videos and images;

2. an asset manager (database) to hold all this information;

3. an output generator that produces the information for the application in a given scenario;

4. an interface to help both domain and SASL experts verify the content and ordering of the SignSupport scenario.

The output from the authoring tool is a well-defined schema for the dialogue together with links to sign language videos and pictures. A mobile application processes the schema in order to present the user interface to the end users (see Figure 2).

\section{RESULTS}

We have created initial versions of all these components. The first fully worked out scenario was a hardcoded Android app for a hospital pharmacy dispensing scenario. An initial version of the authoring tool has been developed for the computer literacy training scenario (ICDL). 


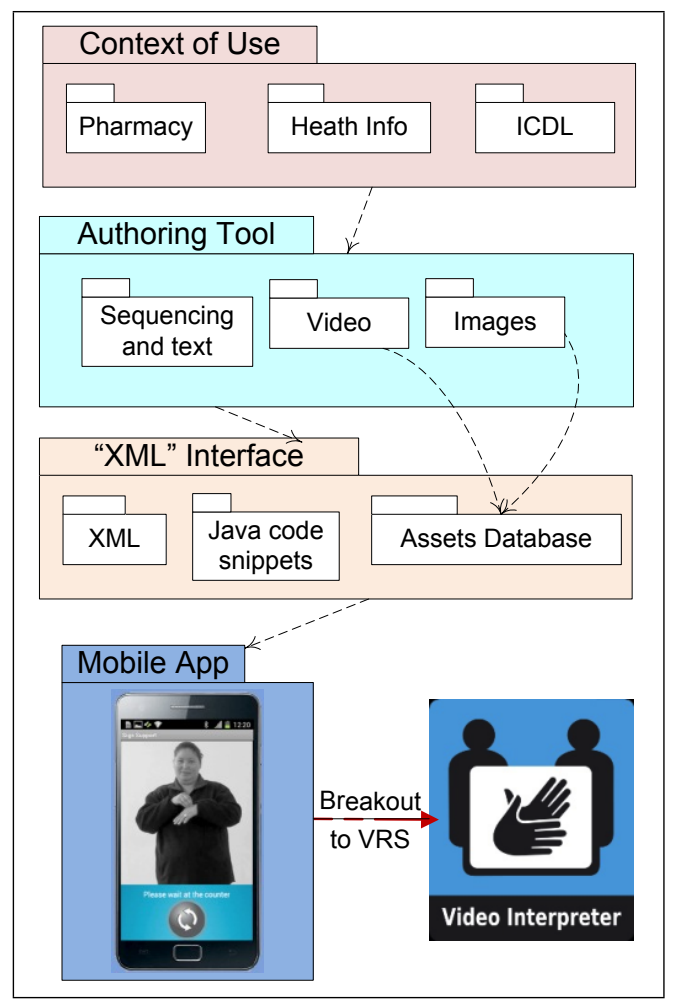

Figure 2: SignSupport conceptual design architecture. The top layer shows the various strictly constrained $\ll$ Contexts of Use» of the system (ICDL is computer literacy training). The $\ll$ Authoring Tool $\gg$ enables a domain expert to put together a sequence of events and displayable assets for each use so as to enable communication. The authoring tool generates the scripts and assets that act as the clearly defined $\ll \mathrm{XML}$ Interface $\gg$ to the «Mobile App》 which runs the actual context specific application on the Deaf user's device. If the communication needs go beyond the limited design context the system makes provision for optional breakout to a Video Relay Service.

\subsection{Initial design pilot: Doctor's consultation}

Our initial design was the scenario of visiting a medical doctor. We performed a detailed design of the doctor's consultation including full scale mock-ups and user testing (Figure 3). Some Deaf users were confused about the idea of entering information about themselves onto a cellphone displayed on the computer screen in order to inform a fictitious doctor about their feigned complaints. As the task they were asked to do carried on they became surer of the setup.

To quote one user:

At first I didn't understand the process and how it worked, what it's meant for

... But after a while I felt more comfortable.

All participants explained that they thought the SignSupport concept could be very useful in daily life, especially to explain invisible things, such as 'headache', 'a blocked nose' or 'a few days'. They mentioned the police station and banks as other places where they would like to use it. When asked about whether they would trust the system to correctly explain their answers to the hearing doctor, they said they had no doubt about it. Another user said:

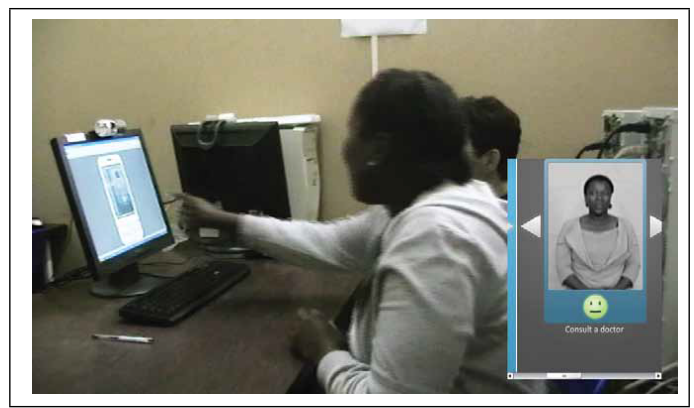

Figure 3: Testing the Medical Consultation scenario. Composite image of video camera recording and computer screen capturing.

With this system you press a button and he knows if you have a headache. I think hearing people may want to use this system as well ... get the right medication.

The trials conclusively showed the usefulness of the approach and Deaf participants expressed a desire to use the application on a mobile phone. A mobile prototype was built on Symbian to allow a Deaf person using SASL to tell a hearing doctor how s/he is feeling and provided a way for the doctor to respond [23]. The prototype embedded SASL videos inside XHTML pages using Adobe Flash. The prototype asked medical questions using SASL videos, organized to identify a medical problem. The answers to the questions were then displayed in English on the phone and shown to the doctor. It was envisaged that a content authoring tool could be used to populate the prototype in a context free manner allowing for plug and play scenarios such as a doctor's consultation, Department of Home Affairs or police station.

Results indicated that most of the Deaf people found the system user friendly, with acceptable levels of sign language clarity and security of private information. They reported that they would consider using the system in real life. However, it became clear that the two-way communication between doctor and patient had too many open-ended possibilities that our system could not support with pre-recorded videos. Together with our Deaf co-designers, we re-focussed the work toward a more limited domain scenario, namely pharmacy dispensing.

\subsection{Pharmacy dispensing}

The re-focus resulted in the design of a communication tool for a simpler dialogue tree in the pharmacy context 24. An industrial design engineer combined Vision in Product Design 25] and traditional human-centred techniques to design a feasible communication tool for a Deaf person to use at the pharmacy. Interviews, storyboards, and role play were the main techniques used to unfold the users' needs and wishes. The investigation revealed that Deaf patients need to understand their medication requirements as prescribed by the doctor and dispensed by the pharmacist clearly. This is a challenge as many Deaf people are functionally illiterate 26]. SignSupport was re-designed to serve as a portable SASL interpreter of a limited commu- 
nication scenario where a Deaf patient communicates with a pharmacist independently. This included medical instruction, warnings, recommendations and usage information. The tool effectively translates medicine instruction given in English text to South African Sign Language videos, which are relayed to a Deaf user on a mobile phone.

A multi-disciplinary collaboration resulted in the iterative development of a mobile communication tool to support a Deaf person in understanding usage directions for medication dispensed at a pharmacy [27. This collaboration improved usability and correctness of the user interface [28. Communication between pharmacists and Deaf patients were studied to extract relevant exchanges between the two users. We incorporated the common elements of these dialogues to represent content in a verifiable manner to ensure that the mobile tool relays the correct information to the Deaf user.

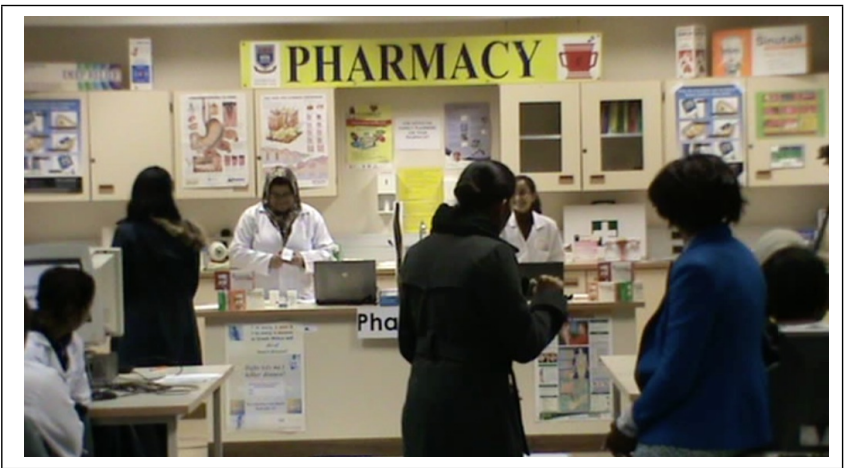

Figure 4: Mock-up of a hospital pharmacy used to testing the pharmacy SignSupport. Staffed by pharmacy students and with Deaf users from DCCT.

A pharmacy setup was recreated (Figure 4) to conduct trials of the tool with groups of end users, in order to collect usability data with recorded participant observation, questionnaires and focus group discussions. The results of the user trials indicated that SignSupport is accessible, intelligible and affordable to Deaf users. Pharmacists reported that SignSupport enabled them to fulfil their professional obligations, which was to ensure that their patients understood their medicine instruction.

The implications of this work highlighted several other issues. Firstly, an affordable and accessible VRS would be needed to be established locally to handle the need for true two-way communication where a Deaf person requires clarification from the pharmacist, and vice versa. Secondly, limitations in mock trials include the satisficing of answers, i.e., responding according to what you believe someone wants to hear. Lastly, participants were neither ill nor dispensing actual medication, so the urgent need for clear communication was absent. Both of the latter issues can only be addressed by taking the application to an actual clinical pharmacy setting. The evaluation of SignSupport design by both Deaf people and pharmacists, in assisting communication was promising and the recommenda- tion was to implement the design for clinical trials. The responsibility for the clinical trial lies with a research pharmacist in collaboration with the rest of the multi-disciplinary team.

\subsection{Authoring computer literacy}

International Computer Driving Licence (ICDL) training has been an ongoing activity at DCCT that was originally requested by the community. The ICDL ${ }^{6}$ is an internationally recognized computer skills certification programme run by the ECDL Foundation 7 . We are collaborating with Computer $4 \mathrm{Kid}^{8}$, an educational ICT company run by educators. The company offers an E-Learner package to assist learners of all ages and educators with obtaining an ICDL qualification. Since there are a number of different lessons in a course, this was an ideal environment to start exploring the creation of an authoring tool. They have given us access to their product and have agreed that we can look into ways of converting some of the support material into a form more suitable for Deaf learners.

Computer literacy for Deaf learners is better facilitated by sign language mediation. At present this is provided by a teacher but this has several drawbacks:

1. It is very demanding on the teacher.

2. Students cannot learn at their own pace.

3. It is expensive.

4. Learning can only occur in class.

A pilot version of the ICDL authoring tool has been completed and tested in the lab (Figure 5). Field trials will begin shortly.

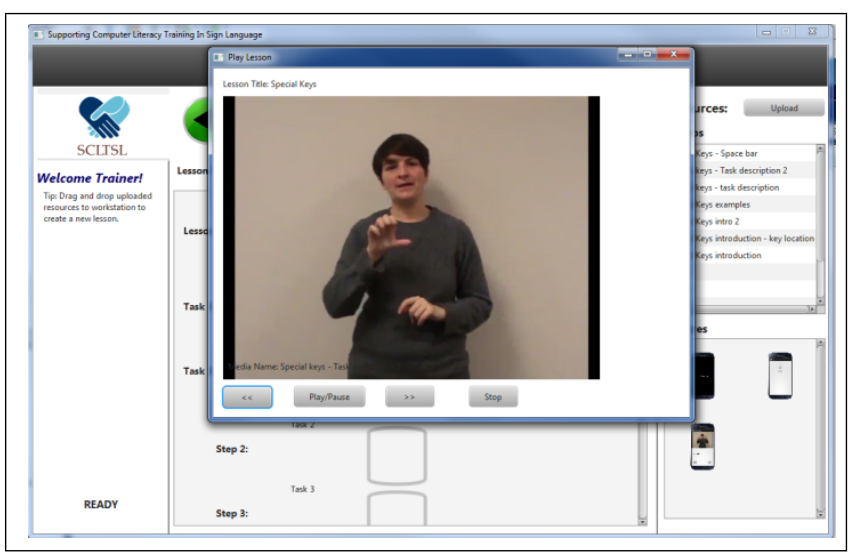

Figure 5: Pilot version of the ICDL Authoring tool. The pop-up shows a video clip being previewed before inclusion. The list of assets that can be included is on the right, while the centre panel shows the structure of the lesson being prepared.

\subsection{Health information}

In the South African healthcare context, many Deaf people cannot acquire accurate information from reliable sources to maintain their health or to participate

\footnotetext{
${ }^{6}$ http://www.icdl.org.za

${ }^{7}$ http://www.ecdl.com

${ }^{8}$ http://www.computers4kids.co.za
} 
in choices of treatment for themselves. Due to barriers to communication and information, many Deaf people acquire healthcare knowledge from Deaf friends who may not have access to the correct information either. This inaccurate information leaves the Deaf person with misunderstandings and misconceptions and can have a long-term impact on their health.

The aim is to develop SignSupport further to assist Deaf people to access accurate healthcare information. Therefore, appropriateness and usability of the health knowledge sources, tools and services will be evaluated together by Deaf people and health knowledge providers. This extension is complementary to the other SignSupport healthcare interventions.

\section{DISCUSSION}

While much progress has been made providing independent communication for Deaf people in limited domains, there are several significant challenges that remain to be addressed in order to provide accessible, affordable and sustainable ICT solutions to communication barriers. We understand that the smart phones currently required to run the resulting communication aids are expensive and to make them affordable we maintain a pool of phones at a community centre for loan to members. We do however expect the cost of phones that can run this system to reduce over time. We have also intentionally focussed on such limited communication domains because we can pre-define a constrained dialogue and pre-record all of the needed sign language videos on the phone without the need to stream video content from the Internet. This significantly reduces the cost of use.

Accessibility of the system is particularly important when dealing with a community that is semiliterate and possesses limited ICT skills. Targeted training of ICT skills using SASL must be part of the delivery of the system. All the initial design work included making sure that Deaf users found the system easy to use. To address SignSupport's limited prerecorded two-way communication, we expect to add a video relay system and will endeavour to produce one that consumes a minimum of bandwidth to minimize usage costs.

The authoring tool is designed to simplify the production and lower the cost of new content for existing and future scenarios. To ensure the sustainability of the system, Deaf people are empowered to identify a scenario, populate a scenario with signed content using the authoring tool, and automatically generate a mobile app to run that content.

Currently, the project is mostly supported by research funding. Noting the importance of ICT-related benefits associated with the communications research endeavours, the Deaf community has assumed payment for their Internet service, thereby moving toward sustainability. A remaining challenge is to devise a sustainable business model with the Deaf community for the co-designed artefacts described herein that can be self-managed by and for Deaf people.

\subsection{Advocating Design within ICT4D}

We regard the field of ICT4D as being inherently multi-disciplinary and we approach it from an action research based point of view; one that leads to designimplement-reflect cycle. It is a research method that is based on a pragmatist epistemology and needs to be seen in the context of experimental computer science (ECS) (Section 2.2).

ECS traces its heritage from engineering where progress is achieved via the design of a novel computing artefact (this is a contested statement-see 29] for a recent survey of the debate). The theoretical branch of Computer Science is mathematics and does not require experimentation for verification. ECS experiments are typically small investigations to verify effectiveness of the artefact in its application area.

Design-based disciplines have generally not been welcomed in academia [30. Buchanan points out that

Fragments of the human power or ability to create have, indeed, moved into universities in the past century or more ... most recently in the form of computer science.

Our conception of design has moved from considering the form and function of an artefact to thinking more of 'the experience of the human beings that make and use them in situated social and cultural environments' 30 .

This is in direct contrast to those ICT disciplines derived from the behavioural sciences, which place the hegemony of theoretical foundations above all else. In Information Systems, like Computer Science, the role of design is also contested, on one side there is the mainly German speaking and Scandinavian 'Wirtschaftsinformatik' approach that favours design science 31 and on the other the mainly 'Anglo-Saxon' approach 32 that argues for the primacy of theory. Österle et al. characterize the second approach as follows:

Rooted in the business school culture, it is based on a behaviorist approach. Rather than aiming at the design of innovative IS, it focuses more on observing IS characteristics and user behavior. [31, p. 7]

This is clearly seen a polemic by Richard Heeks, a leading scholar in ICT4D, who quotes Marx's epitaph "The philosophers have only interpreted the world, in various ways. The point, however, is to change it.", only to reject this position comprehensively. He goes on:

There has been a bias to action, not a bias to knowledge. We are changing the world without interpreting or understanding it. Most of the ICT4D research being produced is therefore descriptive not analytical. It might make some interesting points but it lacks sufficient rigor to make its findings credible ... It has a close-to-zero shelf life. The pictorial analogy of such work is that of stones being thrown into a pond, each one making a ripple but then sinking without 
trace ... a contribution is generally possible only where the research draws on some preexisting conceptual framework. 33.

We quote it at length to show how polemical such standpoints become. In listing disciplines that might contribute to the underlying theories of ICT4D research it is notable that there no mention of design 9 . Heeks [33. does not argue for a particular theoretical position to be derived from the underlying foundations, rather he seems to advocate a patterning approach: 'in this situation, the following theory is a good one to apply'. Theory essentially plays the role of a metaphysical certainty and ultimately this is the Platonic position: if we look at individual objects in experience we can only aspire to 'opinions', while knowledge is about 'eternal, unchanging things' 34, p. 479-480].

In a slightly later opinion piece, Heeks' position seems to have moderated [35. Design is foregrounded and the emphasis for ICT4D is firmly on benefitting deprived communities. The underlying contributory disciplines now include Computer Science (along with Development Studies, while still giving primacy to Information Systems). It is argued however that the Information Systems perspective can lose engagement with the computational artefact, becoming a social science that it fails to engage with the technology. Our own experience has been that the issue is not so much failure to engage with technology but rather to regard it as a given: unchanging and fixed rather than malleable and the outcome of creative design and innovation [36].

\subsection{Pragmatism and methodological pluralism}

The position we are taking is that there should be no bias - neither towards action nor to knowledge - in ICT4D, both action and theory matter equally. Such is the position of pragmatism: it conflates doing and knowing. It is apparent that the position quoted above is not a pragmatist one, while design is clearly a pragmatic discipline [37. In their article on 'technology as experience', McCarthy and Wright put it this way:

In contrast with other philosophical approaches whose starting point is a theory of knowledge or subjective states, pragmatism starts with experience and, by committing to a holistic, relational worldview, tries to ensure that experience is never reduced to categories such as knowledge, behavior, or feelings. [38, p. 54]

We also believe firmly in a pluralistic method. Donner and Toyama 39 point to an approach that embraces methodological pluralism while still aiming at cumulative growth of knowledge. Law advocates 'method assemblage' 40].

\subsection{Design 'in the wild'}

A more recent trend in Human-Computer Interaction (HCI) which is related to our approach is that of design

\footnotetext{
${ }^{9}$ To be clear: we agree that the field of ICT4D is littered with failures, and we are not advocating an anything-goes approach.
}

'in the wild' 41, 42, 43] 44. This depends on deployment of prototypes in real settings where the artefacts are meant to be used. 'Wild theory' 41] is concerned with thinking about design; it is less about knowledge as predictive and more about the interconnectedness of design, technology and social behaviour.

Design in the wild touches down in the 'wild' very briefly, interventions are typically short [44. This is a crucial difference with the method we adopt; Community-Based Co-Design implies a long term commitment beyond the initial design into successive cycles of innovation and evaluation.

\subsection{Towards reciprocity and community}

The further danger to this privileging of theory is that it is damaging to realising the needs of the researched people, whose aims, as Mulemi 45] points out, are 'solving their existential problems.' We thus argue that the 'D in ICT4D' stands for realized development and not 'linking concepts in development studies to this research domain' 33].

Finally we believe that the question of privileging theory is also an ethical one. Our co-designers have busy lives; with our approach, they commit to longterm collaboration. What are they going to get out of this? Pleasure in seeing our students graduate? Not really. Appreciation of a good theory? Unlikely. We believe in an ethics of reciprocity and the best way is to create something useful as a direct consequence of the research, something that would be impossible if we privilege theory over action. We strive for a mutually beneficial relationship [46] 47].

In this sense we are with Marx. As an approach to societal change we believe that theoretical studies run the risk of feeding policies rather than implementation. We acknowledge that the alternative approach we are advocating could merely lead to small projects which run the risk of never being scaled up nor generalized and forever remaining pilot studies. We guard against this by triangulating our studies (applying SignSupport to different fields of application) and actively pursuing sustainable implementation, for example through training the users to take over the system and make it a tool in their hands to generate new application areas.

\section{CONCLUSION}

Deaf people are entitled to accessible, affordable and sustainable ICT systems. The Community-Based CoDesign method has enabled us bridge communication gaps for and with a marginalised Deaf community. It describes a process for arriving at suitable designs for the types of design problems that arise in ICT4D.

In this paper we showed how CBCD led to the production of a series of SignSupport prototypes. We have implemented SignSupport for both medical and pharmacy interactions, and the pharmacy scenario is now ready to be trialled at an actual pharmacy. We have completed and tested our first designs of a 
computer literacy training application to assist us in delivering the International Computer Driver's License course for Deaf learners. We have built a prototype of an authoring tool to generate the content for this mobile training aid.

Because of this opening up of the scope of SignSupport our experience shows that CBCD is a transferable co-design approach. The method has also been applied in rural Namibia where we explicitly examined the issue of transferability of CBCD to different contexts 48].

The next step in examining the transferability of our co-design approach is to develop an authoring tool that will enable us to create content for multiple application areas. Once we can do that it will be easier to examine SignSupport's scope with multiple scenarios. This theoretical advance will also serve to make the artefacts more useful for Deaf people. We also envisage that this generalisation process will pave the way for multiple platforms and even multiple languages.

CBCD has shown itself to be a technique for engaging a community in a way that is democratic and empowering. In this case members of the Deaf community-who do not have a high school education, and with whom many of us can only communicate via an interpreter-were able to participate in the design of sophisticated ICT systems as empowered partners. We have shown elsewhere what the theoretical grounds are for obtaining this kind of community consensus [49]. It involves a reflection on exactly what is meant by 'participation' in an African context; a context in which 'community' is given a particular content through the lived experience of 'ubuntu' or 'palaver'. We emphasize throughout the importance of mutual learning and a reflection on roles [50].

We advanced our academic endeavours while producing useful communication access for Deaf people. We hope this article demonstrates that a communitybased co-design approach can move us towards accessible, affordable and sustainable information and communication access for Deaf people in South Africa.

\section{ACKNOWLEDGMENTS}

Our close collaborator and colleague Dr Adinda Freudenthal (Technical University of Delft, Faculty of Design) passed away shortly before the writing of this paper. Her influence on shaping our understanding of design thinking is deep and she is greatly missed.

Our thanks go to the staff of the Deaf Community of Cape Town for being our co-designers. If the conventions of academic publishing were otherwise they would be co-authors as well.

Finally, we thank our principal funders, the South Africa Netherlands Research Programme on Alternatives in Development (SANPAD).

\section{REFERENCES}

[1] M. Heap and H. Morgans. "Language policy and SASL interpreters in the public service". Disability and social change: A South African agenda, pp. 134-147, 2006.

[2] T. Reagan. "South African Sign Language and language-in-education policy in South Africa". Stellenbosch Papers in Linguistics, vol. 38, pp. 165-190, 2008.

[3] "Minister Paul Mashatile confirms regulation of Language Practitioners is imminent", December 2013. URL https://www.dac.gov.za/content/ministerpaul-mashatile-confirms-regulation-languagepractitioners $\%$ E2\%80\%99-imminent

[4] P. Benjamin. "Reviewing universal access in South Africa". The Southern African Journal of Information and Communication, vol. 2, 2009.

[5] M. Msimang. "Universal access and universal service: An overview". Trends in Telecommunication Reform, pp. 29-50, 2003.

[6] Universal Service Agency. "Discussion paper on definition of universal service and universal access in telecommunications in South Africa". Government Gazette, vol. 400, no. 19397, October 1998.

[7] National Development plan: Vision for 2030. SA National Planning Commission, 2011.

[8] Federal Communications Commission Consumer and Governmental Affairs Bureau. "Consumer guide: Video relay services". January 2012.

[9] D. Samant, R. Matter and M. Harniss. "Realizing the potential of accessible ICTs in developing countries". Disability and Rehabilitation: Assistive Technology, vol. 8, no. 1, pp. 11-20, 2013.

[10] H. Kacorri, P. Lu and M. Huenerfauth. "Evaluating facial expressions in American sign language animations for accessible online information". In Universal Access in Human-Computer Interaction. Design Methods, Tools, and Interaction Techniques for eInclusion, pp. 510-519. Springer, 2013.

[11] J. McKay and P. Marshall. "The dual imperatives of action research". Information Technology $\&$ People, vol. 14, no. 1, pp. 46-59, 2001.

[12] P. Reason and H. Bradbury. The SAGE handbook of action research: Participative inquiry and practice. Sage, 2013.

[13] G. R. Hayes. "The relationship of action research to human-computer interaction". ACM Transactions on Computer-Human Interaction (TOCHI), vol. 18, no. 3, p. 15, 2011.

[14] G. R. Hayes. "Taking action in your research". interactions, vol. 19, no. 4, pp. 50-53, 2012.

[15] J. Dewey. The quest for certainty: A study of the relation of knowledge and action: Gifford lectures 1929. George Allen \& Unwin Limited, 1930.

[16] R. Heeks. "Information systems and developing countries: Failure, success, and local improvisations". The information society, vol. 18, no. 2, pp. 101-112, 2002.

[17] E. H. Blake, W. D. Tucker, M. Glaser and A. Freudenthal. "Deaf telephony: Community-based co-design (case study)". 2011.

[18] T. Reitmaier, N. J. Bidwell and G. Marsden. "Situating digital storytelling within African communities". International Journal of Human-Computer Studies, vol. 69, no. 10, pp. 658-668, 2011. 
[19] D. Ramachandran, M. Kam, J. Chiu, J. Canny and J. F. Frankel. "Social dynamics of early stage co-design in developing regions". In Proceedings of the SIGCHI conference on human factors in computing systems, pp. 1087-1096. ACM, 2007.

[20] D. Yoo, A. Huldtgren, J. P. Woelfer, D. G. Hendry and B. Friedman. "A value sensitive action-reflection model: Evolving a co-design space with stakeholder and designer prompts". In Proceedings of the SIGCHI conference on human factors in computing systems, pp. 419-428. ACM, 2013.

[21] P. Marti and L. J. Bannon. "Exploring user-centred design in practice: Some caveats". Knowledge, technology $\&$ policy, vol. 22, no. 1, pp. 7-15, 2009.

[22] Y. Rogers and G. Marsden. "Does he take sugar? Moving beyond the rhetoric of compassion". interactions, vol. 20, no. 4, pp. 48-57, 2013.

[23] M. Mutemwa and W. D. Tucker. "A mobile Deafto-hearing communication aid for medical diagnosis". 2010 .

[24] P. Chininthorn, M. Glaser, A. Freudenthal and W. D. Tucker. "Mobile communication tools for a South African Deaf patient in a pharmacy context". 2012.

[25] P. Hekkert and M. Van Dijk. "Designing from context: Foundations and applications of the ViP approach". In Designing in Context: Proceedings of Design Thinking Research Symposium, vol. 5, pp. 383-394. 2001.

[26] M. Glaser and T. Lorenzo. "Developing literacy with Deaf adults". Disability and social change: A South African agenda, pp. 192-205, 2006.

[27] M. B. Motlhabi, M. Glaser and W. Tucker. "SignSupport: A limited communication domain mobile aid for a Deaf patient at the pharmacy". In Proc. SATNAC, pp. 173-178. 2013.

[28] M. B. Motlhabi, W. D. Tucker, M. B. Parker and M. Glaser. "Improving usability and correctness of a mobile tool to help a deaf person with pharmaceutical instruction". In Proceedings of the 4th Annual Symposium on Computing for Development, p. 13. ACM, 2013.

[29] M. Tedre. "Computing as a science: A survey of competing viewpoints". Minds and Machines, vol. 21, no. 3, pp. 361-387, 2011.

[30] R. Buchanan. "Design research and the new learning". Design issues, vol. 17, no. 4, pp. 3-23, 2001.

[31] H. Österle, J. Becker, U. Frank, T. Hess, D. Karagiannis, H. Krcmar, P. Loos, P. Mertens, A. Oberweis and E. J. Sinz. "Memorandum on design-oriented information systems research". European Journal of Information Systems, vol. 20, no. 1, pp. 7-10, 2011.

[32] R. Baskerville, K. Lyytinen, V. Sambamurthy and D. Straub. "A response to the design-oriented information systems research memorandum". European Journal of Information Systems, vol. 20, no. 1, pp. 11-15, 2011

[33] R. Heeks. "Theorizing ICT4D research". Information technologies and international development, vol. 3, no. 3, pp. 1-4, 2006.

[34] T. Griffith and G. Ferrari. Plato: 'The Republic'. Cambridge University Press, 2000.
[35] R. Heeks. The ICT4D 2.0 manifesto: Where next for ICTs and international development? University of Manchester. Institute for development policy and management (IDPM). Development informatics group, 2009.

[36] E. H. Blake and W. D. Tucker. "Socially aware software engineering for the developing world". 2006.

[37] A. R. Hevner. "A three cycle view of design science research". Scandinavian journal of information systems, vol. 19, no. 2, p. 4, 2007.

[38] J. McCarthy and P. Wright. "Technology as experience". interactions, vol. 11, no. 5, pp. 42-43, 2004.

[39] J. Donner and K. Toyama. "Persistent themes in ICT4D research: Priorities for inter-methodological exchange". 57th Session of the International Statistics Institute, Durban, South Africa, 2009.

[40] J. Law. After method: Mess in social science research. Psychology Press, 2004.

[41] Y. Rogers. "Interaction design gone wild: Striving for wild theory". Interactions, vol. 18 , no. 4 , pp. 58-62, 2011.

[42] A. Chamberlain, A. Crabtree, T. Rodden, M. Jones and Y. Rogers. "Research in the wild: Understanding 'in the wild' approaches to design and development". In Proceedings of the Designing Interactive Systems Conference, pp. 795-796. ACM, 2012.

[43] A. Crabtree, A. Chamberlain, R. E. Grinter, M. Jones, T. Rodden and Y. Rogers. "Introduction to the special issue of 'The Turn to The Wild"'. ACM Transactions on Computer-Human Interaction (TOCHI), vol. 20, no. 3, p. 13, 2013.

[44] A. Crabtree, A. Chamberlain, M. Davies, K. Glover, S. Reeves, T. Rodden, P. Tolmie and M. Jones. "Doing innovation in the wild". In Proceedings of the Biannual Conference of the Italian Chapter of SIGCHI, p. 25. ACM, 2013.

[45] B. A. Mulemi. "Salvaging African perspectives of reality via Afro-centric and intersubjective methodologies". In 4th European Conference on African Studies. 2011.

[46] D. Bridges and S. McGee. "Collaborative Inquiry". In Creative Spaces for Qualitative Researching, pp. 213-222. Springer, 2011.

[47] S. Maiter, L. Simich, N. Jacobson and J. Wise. "Reciprocity: An ethic for community-based participatory action research". Action research, vol. 6, no. 3, pp. 305-325, 2008.

[48] H. Winschiers-Theophilus, N. Winschiers-Goagoses, K. Rodil, E. Blake and T. Zaman. "Moving away from Erindi-roukambe: Transferability of a rural community-based co-design". In IFIP WG 9.4: 12th international conference on social implications of computers in developing countries, pp. 363-374. 2013.

[49] H. Winschiers-Theophilus, N. J. Bidwell and E. Blake. "Community consensus: Design beyond participation". Design Issues, vol. 28, no. 3, pp. 89-100, 2012.

[50] H. Winschiers-Theophilus, N. J. Bidwell and E. Blake. "Altering participation through interactions and reflections in design". CoDesign, vol. 8, no. 2-3, pp. 163-182, 2012 . 